\title{
OSTEOPOROSIS - STATISTICAL DATA FOR PATIENTS WITH OSTEO- POROSIS IN THE PERIOD FROM 2020 AND THE CURRENT 2021
}

\author{
Jihe $\mathrm{Zhu}^{1}$, Blagica Arsovska ${ }^{1,2}$ and Kristina Kozovska ${ }^{1,3}$ 凶 \\ ${ }^{1}$ Faculty of Medical Sciences, University Goce Delchev, Shtip, Republic of Macedonia, Macedonia \\ ${ }^{2}$ Institute of Biology, Faculty of Natural Sciences and Mathematics, Skopje, Republic of Macedonia, Macedonia \\ ${ }^{3}$ Medicine Faculty, St. Cyril and Methodius University of Skopje, Republic of Macedonia, Macedonia
}
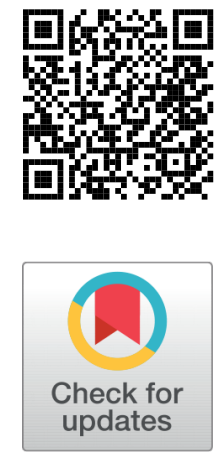

Received 5 July 2021

Accepted 26 July 2021

Published 31 July 2021

Corresponding Author

Kristina Kozovska, tongdatang-tc

m@hotmail.com

DOI $10.29121 /$

granthaalayah.v9.i7.2021.4119

Funding: This research received no specific grant from any funding agency in the public, commercial, or not-for-profit sectors.

Copyright: (C) 2021 The Author(s). This is an open access article distributed under the terms of the Creative Commons Attribution License, which permits unrestricted use, distribution, and reproduction in any medium, provided the original author and source are credited.

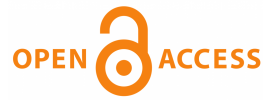

\section{ABSTRACT}

About 120.000 women in Macedonia suffer from osteoporosis. These statistics of the World Health Organization are just a warning about the need for treatment and prevention of this disease. For this research were analyzed statistical data for patients with osteoporosis in the period from 2020 and the current 2021. The data were taken from PHI Medika - Strumica, R.N. Macedonia and the Faculty of Medicine, Skopje RS Macedonia. From the obtained data from 2020 and 2021 for the number of examinations that have been performed in patients with osteoporosis over 50 years, in 2020, out of a total of 542 examinations, 523 are women diagnosed with osteoporosis and 19 are men. In the current 2021, out of a total of 115 examinations, 112 are women and 3 men are registered with osteoporosis. From the obtained data from the PHI Medika - Strumica, in 2020 , out of a total of 792 examinations, 762 are women diagnosed with osteoporosis and 30 are men. In the current 2021, out of a total of 256 examinations, 250 are women and 6 men. In women osteoporosis is significantly more common than in men. From the hospitalized patients with hip fracture because of osteoporosis, $3.4 \%$ of those who are hospitalized are patients aged from 60 to 69 years, $30.6 \%$ are aged from 70 to 79 years, $66 \%$ are patients aged $80+$ years. Age also plays an important role in osteoporosis and fractures. Older people are more likely to need hospital care than younger people.

Keywords: Osteoporosis, Fractures, Statistics, Macedonia

\section{INTRODUCTION}

Osteoporosis is a chronic bone disease, often referred to as the silent epidemic of the 21 st century. It is a disease that manifests itself by a decrease in bone density, which makes them more porous. The process of aging and calcium loss is a normal physiological process that takes place throughout life, but when the loss of bone tissue becomes greater than the formation, osteoporosis occurs. 
Early detection of this disease is very important to prevent the consequences. A person can not detect this disease on their own until they get a fracture, so it is necessary to consult a doctor specialized in this area. The population over the age of 35, which have at least two of the following risk factors, are best to consult a doctor.

Early menopause, thyroid disease, poor physical activity, prolonged sitting position, genetic predisposition, use of hormones, women, low body weight, use of alcohol, cigarettes, caffeine, chronic use of corticosteroids and insufficient dietary calcium, insufficient vitamin intake D.

Normally, the decrease in bone density occurs slowly, and the disease is asymptomatic. For patients it can be confusing bone pain with the weather change, changes in posture, brittle nails and hair, tooth decay. Patients can get osteoporosis and have no symptoms for years. Spinal fractures, which are one of the most common complications of the disease and cause back pain, occur without or after minimal trauma. They are most common on the lumbar and lower thoracic vertebrae. Acute pain develops locally and usually subsides after a few days or weeks. The main symptoms that are felt are bone pain or tenderness, minor fractures with little or no trauma, loss of height over time, improper posture and hump.

Several diagnostic procedures play an important role in the diagnosis, such as bone X-rays, scintigraphic skeletal examination, laboratory tests, bone density tests.

The main goal in the prevention and treatment of postmenopausal osteoporosis is to reduce the frequency of osteoporotic fractures, which are largely responsible for morbidity and indirectly lead to mortality-related conditions.

Despite the fact that osteoporotic fractures are most common in women over the age of 65 and treatment has been shown to be effective in this population, the most commonly available therapies are to prevent, slow down or replace bone loss when treatment begins around the age of 50. People who have been diagnosed with osteoporosis have access to a range of medications and supplements that can stop the disease from developing and improve bone density. Medicines are usually in the form of tablets, and there are injectable and infusion forms of medicines. It is important that the choice of therapy is tailored to the specific medical needs of the patients and their lifestyle. The risk of osteoporosis is reduced with regular physical activity and a healthy diet. Vegetables, rich in vitamins and minerals (vitamin D and calcium), are especially useful, and regular exposure to sunlight is recommended. "NORA-NonGovernmental Organization for Rheumatism and Arthritis-Brochure" (2018) "Association for Emancipation Solidarity and Equality of Women in the Republic of Macedonia - ESE-Brochure" (2018)

\section{MATERIAL AND METHODS}

As a working method was used analysis of statistical data for patients with osteoporosis in the period from 2020 and the current 2021. The data are taken from PHI Medika - Strumica, RN. Macedonia and the Faculty of Medicine, Skopje RN Macedonia 
The data are presented in tables and graphical presentation.

\section{RESULT AND DISCUSSION}

\begin{tabular}{ccc}
\hline Table 1 Number of examinations in patients with osteoporosis 50+ years old \\
\hline Gender & $\mathbf{2 0 2 0}$ & $\mathbf{2 0 2 1}$ \\
\hline Male & 19 & 3 \\
\hline Female & 523 & 112 \\
\hline Total & 542 & 115 \\
\hline
\end{tabular}

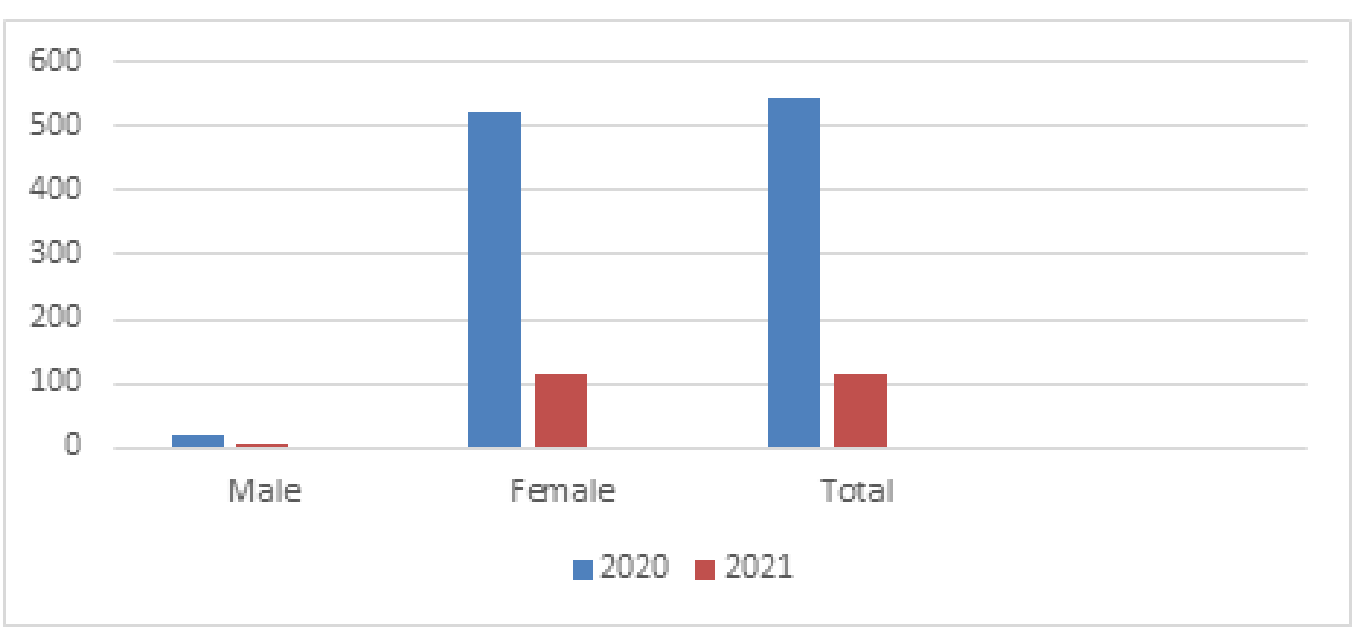

Graph 1: Number ofexaminations in patients with osteoporosis 50+ years old

Table 2 Number of examinationsin patients with osteoporosis

\begin{tabular}{ccc}
\hline Gender & $\mathbf{0 3 . 0 1 . 2 0 2 0 - 2 4 . 1 2 . 2 0 2 0}$ & $\mathbf{2 1 . 0 1 . 2 0 2 1 - 1 0 . 0 4 . 2 0 2 1}$ \\
Male & 30 & 6 \\
\hline Female & 762 & 250 \\
Total & 792 & 256 \\
\hline
\end{tabular}

Table 3 Hospitalized patientsafter hip fracture because of osteoporosis

\begin{tabular}{cc}
\hline Age & Percentage of patients \\
$60-69$ & $3,4 \%$ \\
$70-79$ & $30,6 \%$ \\
$80+$ & $66 \%$ \\
\hline
\end{tabular}




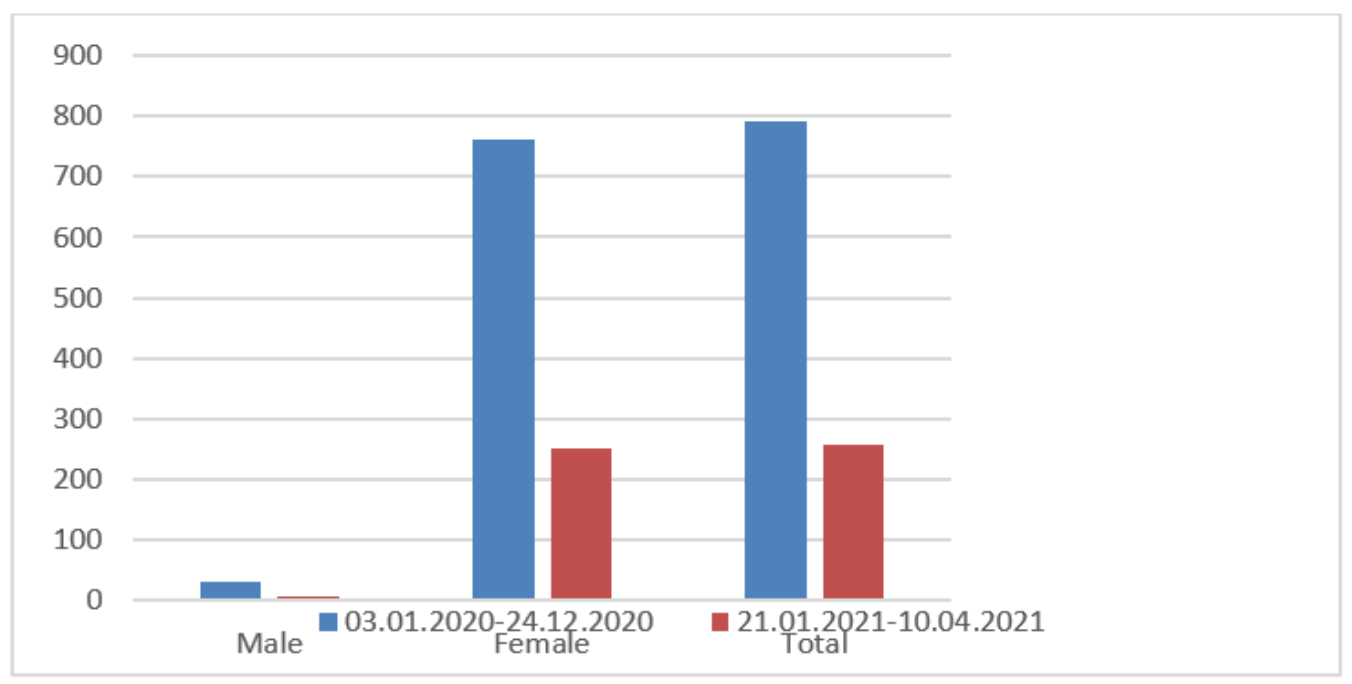

Graph 2: Number of examinationsin patients with Osteoporosis

Statistical research and obtained data on the number of examinations performed on patients with osteoporosis over 50 years in R. Northern Macedonia are shown in Table 1 and Graph 1 . The data are taken from the Faculty of Medicine, Skopje from 2020 and 2021.

It can be noted that osteoporosis is significantly more common in women than in men. In 2020 of total 542 examinations in patients with osteoporosis with $50+$ years old, there were 19 men and 523 women. In 2021 of total 115 patients, 3 were male and 112 female.

In the current 2021, examinations were made from January to April and in this period the increase in women (250) diagnosed with osteoporosis is much higher than in men (6). The osteoporosis is more common in women because after the age of 35 they lose $1 \%$ of bone mass per year and due to lack of estrogen during menopause.

Statistical surveys of hospitalized patients in R. Northern Macedonia after hip fracture are shown in Table 3 . The data are taken from the Medical Faculty, Skopje.

The patients were divided into three age groups. 3.4\% of the patients aged from 60 to 66 needed hospitalization after hip fracture due to osteoporosis. $30.6 \%$ of the patients aged $70-79$ and $80 \%$ of the patients aged above 80 were hospitalized.

From the obtained data it can be seen that age also plays an important role in osteoporosis and fractures. Older people are more likely to need hospital care than younger people.

\section{CONCLUSION}

By introducing a mandatory examination in the riskiest groups of patients, it would be mandatory to increase the percentage of early detection of the disease and its appropriate treatment, in order to prevent the occurrence of fractures and prevent complications from them. All this will contribute to great savings for health system. 
Osteoporosis is becoming a major social and health problem, affecting over 200 million people worldwide.

Global life expectancy increases the number of adults who are at greatest risk.

\section{REFERENCES}

Association for Emancipation Solidarity and Equality of Women in the Republic of Macedonia - ESE-Brochure. (2018).

NORA-Non-Governmental Organization for Rheumatism and Arthritis-Brochure. (2018). 